\title{
Effects of pressurized steam-treated Corni Fructus extract on osteoblast differentiation and osteoclast formation
}

\author{
Hye-Mi Park, Joo-Heon Hong * \\ Department of Food Science and Technology, Daegu Catholic University, Gyeongsan 38430, Korea
}

\begin{abstract}
This study investigated the effects of pressurized steam-treated Corni Frutus (PSC) extract on osteoblast differentiation and osteoclast formation. The osteoblast differentiation effect of the extract was evaluated by measuring cellular alkaline phosphatase (ALP) activity, cell matrix ALP staining, alizarin Red S staining and von Kossa staining on proliferating MC3T3-E1 osteoblast cells. The results confirmed that ALP activity, cell matrix ALP staining, alizarin Red S staining and von Kossa staining were all increased as proliferation increased from 1 to 14 days, without cytotoxicity. The osteoclast formation effect of the PSC extract was evaluated by measuring the cellular tartrate-resistant acid phosphatase (TRAP) activity and cell matrix TRAP staining on receptor activator of nuclear factor kappa-B ligand (RANKL)-induced RAW264.7 osteoclast cells. Treating RAW264.7 cells with RANKL for 7 days increased matrix staining for TRAP and cellular TRAP activity. The PSC extract decreased these changes in a concentration-dependent manner. Therefore, PSC is expected to be a natural source for developing health functional foods and medicinal agents to prevent bone-related diseases, such as osteoporosis, by increasing osteoblast differentiation and reducing osteoclast activity.
\end{abstract}

Key words : Corni Fructus, osteoblast, osteoclast, alkaline phosphatase, tartrate-resistant acid phosphatase

\section{Introduction}

Aging is an inevitable process for all living organisms (1). Infertility, growth arrest, hypoactivity, skin atrophy, premature thymic involution, arteriosclerosis, osteoporosis, and pulmonary emphysema are all associated with human aging (2). Bone mass is maintained by a homeostatic balance between the activities of osteoclasts, which resorb bone, and those of osteoblasts, which make bone. The balance between both cells is controlled by various hormones and cytokines. Excessive osteoclast activity leads to bone loss in pathologic or inflammatory conditions, such as rheumatoid arthritis and postmenopausal osteoporosis $(3,4)$. Osteoporosis is a disease which is an increasing problem in our aging society (5). When bone metabolism is homeostatic, normal bone is maintained

*Corresponding author. E-mail : jhhong@cu.ac.kr

Phone : 82-53-850-3218, Fax : 82-53-850-3218

Received 27 February 2018; Revised 24 March 2018; Accepted 28 March 2018.

Copyright (c) The Korean Society of Food Preservation. All rights reserved.
(6). When the balance is broken due to various diseases, aging, smoking, stress, or sudden estrogen depletion of women, bone absorption is increased relative to bone formation, resulting in bone loss $(6,7)$. Osteoporosis can easily cause fractures, even in the case of mild impacts, and the bone mass per unit volume decreases without significant changes in the chemical composition of the bone (8). Osteoclasts are differentiated and activated by the receptor activator of nuclear factor kappa-B ligand (RANKL) that is secreted by osteoblasts. Activated osteoclasts form an actin ring composed of a fibrous actin sequence between the cell membrane and bone matrix. They secrete proteases and protons, thereby absorbing bone matrix and reducing bone density (9). To inhibit bone resorption, studies are under way to inhibit the early stage of differentiation that blocks the conversion from osteoclast precursor cells to osteoclasts, or to induce the death of differentiated osteoclasts, thereby inhibiting the bone resorption process $(10,11)$. Recently, there is growing concern about the relationship between oxidative stress and osteoporosis (12). In women with osteoporosis, blood concentrations of antioxidants are decreased (13), and bone 
mineral density is increased due to antioxidant vitamin intake (14).

Corni Fructus is the fruit of Cornus officinalis Sieb. Et Zucc, which is part of the Cornaceae family, commonly known as dogwoods (15). Clinically, it is one of the most popular and widely used herbal medicines in the world and can be used in medicine, food sanitation, and cosmetics $(16,17)$. Corni Fructus contains gallic acid, malic acid, tartaric acid, ursolic acid, 5-hydroxymethylfurfural, morroniside, loganin, and sweroside (18-20). This herb has been used traditionally for mitigating tinnitus, improving impotence, and decreasing excessive urination (19). Corni Fructus also has antioxidant (21), antidiabetic (22), and antineoplastic effects (23).

Our previous study showed that treating Corni Fructus with pressurized steam significantly changed the total extractable phenolic and bioactive compounds (i.e., gallic acid, 5-hydroxymethylfurfural, loganic acid, morroniside, and loganin) (24). Also, the protective effects against $\mathrm{H}_{2} \mathrm{O}_{2^{-}}$ induced cytotoxicity in L132 cells treated with pressurized steam-treated Corni fructus (PSC) extract increased with increasing treatment times. Thus, the current study was designed to examine the effects of the PSC extract on osteoblast differentiation and osteoclast formation.

\section{Materials and methods}

\section{Materials}

Corni Fructus without seeds was purchased from a local supermarket (Uiseong, Korea). The samples were treated by hot air-drying at $50^{\circ} \mathrm{C}$ for $24 \mathrm{~h}$, which was terminated when the moisture content, measured using an infrared moisture analyzer (MB45, Ohaus Inc., Pine Brook, NJ, USA), reached $10 \%$. The treated samples were used for the pressurized-steam treatment.

\section{Preparation and extraction}

Dried Corni Fructus (100 g) was soaked with distilled water $(1: 2, \mathrm{w} / \mathrm{v})$ for $1 \mathrm{~h}$ at $25^{\circ} \mathrm{C}$, drained, and treated with pressurized steam $\left(121{ }^{\circ} \mathrm{C}, 1.2 \mathrm{~kg}_{\mathrm{f}} / \mathrm{cm}^{2}\right.$ for $\left.2 \mathrm{~h}\right)$. The PSC sample was hot-air dried at $50^{\circ} \mathrm{C}$ for $12 \mathrm{~h}$ to adjust the moisture content to $10 \%$ as measured using an infrared moisture analyzer (MB45, Ohaus Inc.). The dried sample was ground using a Lab Use grinder (RT-04, Mill Powder Tech, Tainan hsien, Taiwan) at $25,000 \mathrm{rpm}$ for $5 \mathrm{~min}$ at $25^{\circ} \mathrm{C}$ and used for the experiments. PSC (15 g) was reflux extracted with
$80 \%$ ethanol $(1: 20, \mathrm{w} / \mathrm{v})$ for $3 \mathrm{~h}$ at $80^{\circ} \mathrm{C}$. The extract was then filtered and then concentrated $(\mathrm{N}-1 \mathrm{~N}$, Eyela, Tokyo, Japan) under reduced pressure. The concentrate was lyophilzed (Free Zone 2.5, Labconco, Kansas, MO, USA) to yield a powder for use.

Osteoblast cell differentiation and treatments

The newborn mouse calvaria preosteoblast cell line, MC3T3-E1 (ATCC CRL 2593), was obtained from the American Type Culture Collection (Rockville, MD, USA). Complete culture medium was a-minimum essential medium (Welgene, Gyeongsan, Korea) containing 10\% fetal bovine serum (Gibco BRL, Grand Island, NY, USA), and 2\% penicillin-streptomycin (Gibco BRL). Cells were plated at a density of $1.0 \times 10^{5}$ cells/well in a 24 -well plate, and maintained at $37^{\circ} \mathrm{C}$ in a humidified incubator (MCO- 18AIC, Sanyo, Sakata, Japan) with a $5 \% \mathrm{CO}_{2}$ atmosphere.

For measuring effects on proliferation and differentiation, MC3T3-E1 cells were maintained in culture medium overnight. The cells were then treated with the PSC extract and differentiation culture medium, containing $10 \mathrm{mM} \beta$ -glycerophosphate (Sigma-Aldrich, St. Louis, MO, USA) and $50 \mu \mathrm{g} / \mathrm{mL}$ L-ascorbic acid (Sigma-Aldrich). The medium was changed every 3 days and cells were harvested at 1, 7, 14, and 21 days. The following parameters were utilized to monitor of the effects of the PSC extract on the differentiation of mouse preosteoblasts: cellular alkaline phosphatase (ALP) activity, cell matrix ALP staining, Alizarin Red S staining, and von Kossa staining.

Osteoclast cell differentiation and treatments

The mouse monocyte cell line, RAW264.7 (KCLB 40071), was obtained from the Korean Cell Line Bank (Seoul, Korea). Complete culture medium for RAW264.7 cells was the same as for MC3T3-E1 cells. Cells were plated at a density of $5.0 \times 10^{5}$ cells/well in a 24 -well plate and maintained at $37^{\circ} \mathrm{C}$ in a humidified incubator with a $5 \% \mathrm{CO}_{2}$ atmosphere.

To assess effects on differentiation, RAW264.7 cells were maintained in culture medium overnight. The cells were then treated with the PSC extract, in differentiation culture medium containing $50 \mathrm{ng} / \mathrm{mL}$ soluble RANKL (PeproTech, Rocky Hill, NJ, USA) and $50 \mathrm{ng} / \mathrm{mL}$ macrophage colony stimulating factor (M-CSF, PeproTech). The medium was changed every 3 days and cells were harvested after 7 days. The following parameters were utilized to assess the effects of the PSC extract on the differentiation of mouse osteoclast cells: cellular tartrate-resistant acid phosphatase (TRAP) activity, and cell 
matrix TRAP staining.

\section{Cell viability}

Cytotoxicity was determined by the MTT (3-(4,5dimethylthiazol-2-yl)-2,5-diphenyltetrazolium bromide) method, as described by Denizot and Lang (25). Osteoblast cells were measured at 3 days, and differentiated osteoclast cell were measured at 7 days, respectively. After treatments, the MTT solution in phosphate-buffered saline (PBS) $(1 \mathrm{mg} / \mathrm{mL}$, Sigma-Aldrich) was added to each well at 1:10 v/v of medium. The cells were incubated for $4 \mathrm{~h}$ at $37^{\circ} \mathrm{C}$, and dimethyl sulfoxide was added to dissolve the formazan crystals. Absorbance was measured at $570 \mathrm{~nm}$ using an Asys microplate reader (Biochrome, Cambridge, UK). Cytotoxicity was calculated as follows: cytotoxicity $(\%)=($ absorbance sample/absorbance control) $\times 100$.

\section{ALP activity}

Cellular ALP activity was determined by the method described by Ozeki et al. (26), using p-nitrophenyl phosphate (Sigma-Aldrich) as the substrate. At 1, 7, 14, and 21 days of differentiation, cells were rinsed twice with PBS, then $0.1 \%$ Triton $^{\mathrm{TM}} \mathrm{X}-100$ in $10 \mathrm{mM}$ sodium phosphate buffer ( $\mathrm{pH}$ 6.8) was added. After mixing gently and heating at $37^{\circ} \mathrm{C}$ for 30 min, glycine (0.1 M, Sigma-Aldrich) and p-nitrophenyl phosphate $(100 \mathrm{mM})$ were added. After mixing gently and heating at $37^{\circ} \mathrm{C}$ for $30 \mathrm{~min}, 1 \mathrm{~N}$ sodium hydroxide was added to stop the reaction. The reaction mixture was transferred to a 96-well plate, and the absorbance was measured at 405 $\mathrm{nm}$ using an Asys microplate reader. ALP activity was calculated as follows: activity $(\%)=($ absorbance sample/ absorbance control) $\times 100$.

\section{Cell matrix ALP staining}

At 14 and 21 days of differentiation, ALP staining was performed using the Leukocyte Alkaline Phosphatase Kit (86R, Sigma-Aldrich). Staining was visualized by light microscopy (TS100, Nikon Eclipse, Tokyo, Japan) and images were acquired with an i-Solution digital camera (IMTcam3, Canon, Tokyo, Japan). Cells with ALP activity were stained red as an indicator of bone nodule areas.

\section{Alizarin Red S staining}

To measure extracellular matrix calcium deposits indicative of bone nodule formation, the cellular matrix was stained using Alizarin Red S dye (Sigma-Aldrich), which combines with calcium in the matrix, as described previously (27). At
14 and 21 days of differentiation, cells were rinsed twice with PBS and then fixed with $2 \%$ formaldehyde. Cells were stained with Alizarin Red S solution (40 mM, pH 4.4) for $40 \mathrm{~min}$ at $25^{\circ} \mathrm{C}$, and rinsed twice with distilled water. Staining was visualized by light microscopy and images were acquired with an i-Solution digital camera. After photographing, 10\% cetylpyridinium chloride (Sigma-Aldrich) in $10 \mathrm{mM}$ sodium phosphate buffer ( $\mathrm{pH}$ 7.0) was added. The liquid containing dissolved Alizarin Red S was transferred to a 96-well plate, and the absorbance was measured at $562 \mathrm{~nm}$ using an Asys microplate reader. The mineralization value was calculated as follows: mineralization $(\%)=($ absorbance sample/absorbance control $) \times 100$. The concentration of Alizarin Red S staining in the samples was determined by comparing the absorbance values with those obtained from Alizarin Red S standards.

\section{von Kossa staining}

Calcium coprecipitates with phosphate ions in the matrix. Thus, von Kossa staining (which stains phosphate ions) was also used to assess mineralization in the cultures, as described by Kwon et al (28). At 14 and 21 days of differentiation, cells were rinsed twice with PBS and then fixed with $2 \%$ formaldehyde. After rinsing twice with distilled water, cells were treated under ultraviolet light with $3 \%$ silver nitrate solution (Sigma-Aldrich) for $1 \mathrm{~h}$ at $25^{\circ} \mathrm{C}$. After rinsing twice with distilled water, staining was visualized by light microscopy and images were acquired with an i-Solution digital camera.

\section{TRAP activity}

Cellular TRAP activity was determined using the method described by Woo et al. (29). At 7 days of differentiation, cells were rinsed twice with PBS, and $0.2 \%$ Triton $^{\mathrm{TM}} \mathrm{X}-100$ solution was added. After mixing gently and heating at $37^{\circ} \mathrm{C}$ for $30 \mathrm{~min}$, TRAP solution $(1.36 \mathrm{mg} / \mathrm{mL}$ 4-nitrophenyl phosphate disodium salt (Sigma-Aldrich) and $10 \mathrm{mM}$ tartrate in $50 \mathrm{mM}$ citrate buffer, $\mathrm{pH} 4.6$ ) were added. After mixing gently and heating at $37^{\circ} \mathrm{C}$ for $30 \mathrm{~min}, 0.1 \mathrm{~N}$ sodium hydroxide was added to stop the reaction. The reaction mixture was transferred to a 96-well plate, and absorbance was measured at $405 \mathrm{~nm}$ using an Asys microplate reader. TRAP activity was calculated as follows: activity (\%)=(absorbance sample/absorbance control) $\times 100$.

\section{Cell matrix TRAP staining}

At 7 days of differentiation, cell matrix TRAP staining was measured using the TRACP \& ALP Double-Stain Kit 
(MK300, Takara Bio, Shiga, Japan). Staining was visualized by light microscopy and images were acquired with an i-Solution digital camera. Products of TRAP activity were stained red, indicating bone nodule areas.

\section{Statistical analysis}

All experiments were carried out in triplicate, and data are reported as means $\pm \mathrm{SD}$. Duncan's multiple-range test was used to adjust for multiple comparisons, and null hypotheses were rejected at the 0.05 level. All data were analyzed using SPSS/Windows software (Version 19.0, IBM, Chicago, IL, USA).

\section{Results and discussion}

\section{Cell viability}

The effect of the PSC extract on the viability of MC3T3-E1 osteoblast cells was determined using the MTT assay. MC3T3-E1 cells are derived from mouse calvaria and have metabolic characteristics similar to osteoblasts such as proliferation, differentiation, and calcification in vivo (30). In particular, MC3T3-E1 cells have a glycoprotein, ALP, in the cell membrane, that is useful in studies related to bone formation (30,31). MC3T3-E1 osteoblast cells were cultured under osteogenic conditions, and treated with $1-1,000 \mu \mathrm{g} / \mathrm{mL}$ of the PSC extract. Our results showed that there was no cytotoxic effect on these cells at the tested concentrations (Fig. 1). After MC3T3-E1 osteoblast cells were cultured for $72 \mathrm{~h}$, the PSC extract at concentrations of 1 and $10 \mu \mathrm{g} / \mathrm{mL}$ showed the most proliferation-stimulating activity (112\% at both concentrations as compared with untreated cells). It is noteworthy that the PSC extract did not show strong activity on MC3T3-E1 osteoblast cells, and cell viability was not promoted in a concentration-dependent manner. In fact, low concentrations had the most significant effects. Therefore, the PSC extract at $10 \mu \mathrm{g} / \mathrm{mL}$ was selected for subsequent experiments.

\section{ALP activity and staining}

ALP is present in the cell membranes of osteoblasts, and is found at high concentrations in the outer membrane of these cells and calcified tissue (32). ALP is marker of osteoblastic activity, and acts as a regulator of transport of inorganic phosphoric acid, and cell division or differentiation during calcification $(31,32)$. To evaluate the effect of the PSC extract on the differentiation of MC3T3E1 osteoblast- like

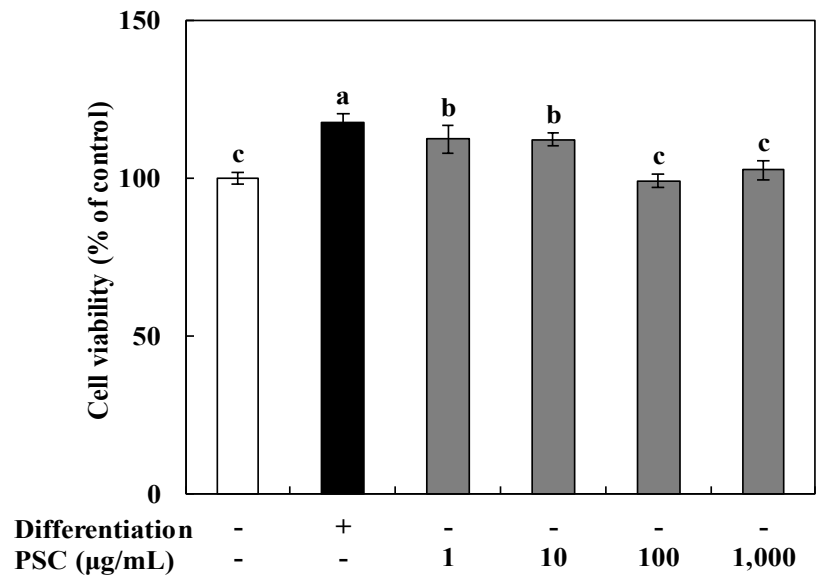

Fig. 1. Effect of pressurized steam-treated Corni Fructus extract on MC3T3-E1 osteoblast cell proliferation at 3 days.

Abbreviations: PSC, pressurized steam-treated Corni Fructus at $1.2 \mathrm{~kg}_{\mathrm{f}} / \mathrm{cm}^{2}$ and $121^{\circ} \mathrm{C}$ for $2 \mathrm{~h}$.

Values are expressed as means \pm SD of triplicate determinations. Bars with different letters indicate significant differences $(\mathrm{p}<0.05)$

cells, ALP activity was evaluated during 1 to 21 days of culturing. MC3T3E1 cells were cultured in differentiation medium ( $\beta$-glycerophosphate and ascorbic acid) and treated with $10 \mu \mathrm{g} / \mathrm{mL}$ of the PSC extract. Differentiation was confirmed with ALP staining (Fig. 2). On day 1, ALP activity did not differ significantly between non-treated and PSC-treated cultures, whereas on days 7 and 14, there were significant increases in ALP activity. This was especially true in the group treated for 14 days with the PSC extract compared with the control. According to Ji et al. (33), the ALP activity was significantly increased in MC3T3E1 cells after 3 days of treatment with a Petasites japonicus extract. ALP activity reached a maximum at 14 days of culturing and decreased thereafter. The results of our study are consistent with these results. Because ALP is secreted as well as being membrane-bound, extracellular ALP activity was also assessed. The influence of PSC extract treatment on ALP activity in the extracellular matrix was measured by ALP staining at $1,7,14$, and 21 days (Fig. 2B). In contrast to the control, ALP activity showed a time-dependent stimulation in response to PSC extract treatment.

\section{Alizarin Red S and von Kossa staining}

Bone cell culture systems are essential tools for investigating of the molecular mechanisms that regulate mineralization of the extracellular matrix (34). Such studies provide fundamental information on biomineralization that is important to understanding basic skeletal (and dental) biology, and to managing mineralization-related pathologies, such as osteomalacia and ectopic calcification. Data on 


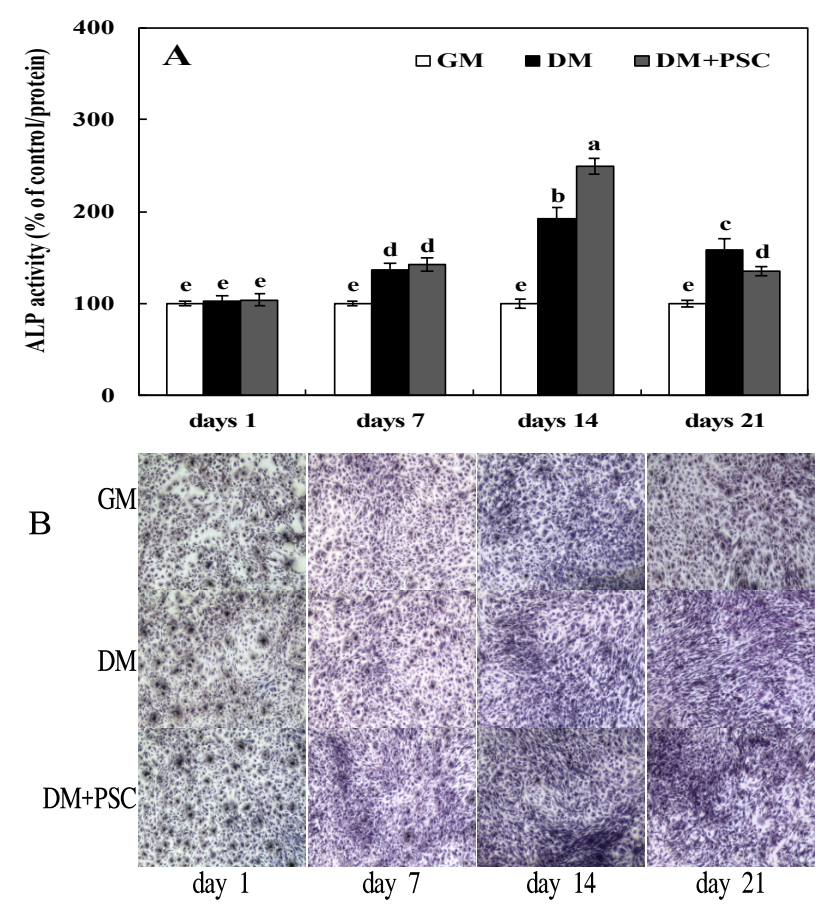

Fig. 2. Alkaline phosphatase (ALP) activity and staining of MC3T3-E1 osteoblast cells after incubation with pressurized steam-treated Corni Fructus extract. (A) Cellular ALP activity, and (B) cell matrix ALP activity staining were measured at 1, 7, 14, and 21 days.

Abbreviations: GM, growth medium; DM, differentiation medium; DM+PSC, differentiation medium with $10 \mathrm{\mu g} / \mathrm{mL}$ pressurized steam-treated Corni Fructus at 1.2 $\mathrm{kg}_{\mathrm{f}} / \mathrm{cm}^{2}$ and $121^{\circ} \mathrm{C}$ for $2 \mathrm{~h}$

Values are expressed as means $\pm \mathrm{SD}$ of triplicate determinations. Bars with different letters indicate significant differences $(\mathrm{p}<0.05)$.

mineralization mechanisms obtained from cell culture models are also valuable for the rational design of bone repair strategies and tissue engineering constructs, and for biomaterial innovation (35). We verified the effects of the PSC extract on osteoblastic differentiation. MC3T3-E1 cells were cultured under osteoblastic conditions and treated with the extract for 12 and 21 days. PSC extract treatment significantly increased mineralization. Specifically, both Alizarin Red S and von Kossa staining revealed an increase in the volume of mineralized nodules following PSC extract treatment (Fig. 3). These results confirm that the PSC extract facilitates osteoblastic differentiation.

\section{Cytotoxicity in RAW264.7 osteoclast cells}

Monocyte/macrophagic RAW264.7 cells have been used previously as a model for osteoclast formation (36). In view of their potential utility for elucidating both essential elements of osteoclast differentiation as well as the mechanism through which the PSC extract might inhibit osteoclast formation, we studied RANKL-induced osteoclast formation.


Fig. 3. Alizarin red S staining and von Kossa staining of MC3T3-E1 osteoblast cells after incubation with pressurized steam-treated Corni Fructus extracts. A, Extracellular matrix mineralization, and cell layer matrix mineralization were measured at 14 and 21 days; B, Alizarin red S quantification was measured at $562 \mathrm{~nm}$ and by observation of mineralization.

Abbreviations: GM, growth medium; DM, differentiation medium; DM+PSC, differentiation medium with $10 \mu \mathrm{g} / \mathrm{mL}$ pressurized steam-treated Corni Fructus at 1.2 $\mathrm{kg}_{\mathrm{f}} / \mathrm{cm}^{2}$ and $121^{\circ} \mathrm{C}$ for $2 \mathrm{~h}$.

Values are expressed as means $\pm \mathrm{SD}$ of triplicate determinations. Bars with different letters indicate significant differences $(p<0.05)$.

Cytotoxicity of RANKL-induced RAW264.7 osteoclast cells treated with $1-1,000 \mu \mathrm{g} / \mathrm{mL}$ of the PSC extract for 7 days was assessed using the MTT assay (Fig. 4). Cells treated with $1,000 \mu \mathrm{g} / \mathrm{mL}$ of the PSC extract showed the greatest viability ( $134 \%$ of untreated cells). These results showed that there was no cytotoxic effect on RANKL-induced RAW264.7 osteoclast cells at the tested concentrations of the PSC extract. Therefore, concentrations of the PSC extract from 1 to 1,000 $\mu \mathrm{g} / \mathrm{mL}$ were selected for subsequent experiments.

\section{TRAP activity and staining}

Osteoclasts are derived from hematopoietic precursors and differentiate from mononuclear macrophages. Differentiation is generally regulated by two cytokines, M-CSF and tumor necrosis factor related activation-induced cytokine (TRANCE, RANKL or ODF) (37). When osteoclasts are differentiated, they form mononuclear proliferating osteocytes (30). But, when cells are fused, they form multi-nucleated mature osteoclasts, which attach to the bone surface and absorb bone 




Fig. 4. Cytotoxicity of pressurized steam-treated Corni Fructus extracts on receptor activator of nuclear factor kappa-B ligand (RANKL)-induced RAW264.7 osteoclast cells at 7 days.

Abbreviations: PSC, pressurized steam-treated Corni Fructus at $1.2 \mathrm{~kg}_{f} \mathrm{~cm}^{2}$ and $121^{\circ} \mathrm{C}$ for $2 \mathrm{~h}$.

Values are expressed as means $\pm \mathrm{SD}$ of triplicate determinations. Bars with different letters indicate significant differences $(p<0.05)$.

$(30,38)$. In addition, osteoclasts have TRAP and calcitonin receptors, and are active in acid production, and TRAP is widely used as a marker for osteoclasts $(38,39)$. we treated RAW264.7 cells with RANKL in the absence or presence of PSC and assessed the TRAP-positive cells present on day 7. Treatment of RAW264.7 cells with soluble human RANKL for 7 days led to a profound differentiation of this monocyte-macrophage cell line into multinucleated, TRAP-positive, osteoclast-like cells when compared with cells without RANKL treatment (Fig. 5A). The extent of staining decreased as the PSC extract concentration increased. As shown in Fig. 5B, cellular TRAP activity with RANKL alone was $148 \%$ of control, and decreased in a concentrationdependent manner: with PSC extract treatment to 142,120 , and 114 and $92 \%$ of untreated cells at $1,10,100$, and 1,000 $\mu \mathrm{g} / \mathrm{mL}$, respectively. Lee et al.(40) reported that, besides their microbicidal properties, reactive oxygen species produced in macrophages and monocytes through RANKL-TRAF6Rac1-NADPH oxidase-dependent pathways may be involved in the mediation of osteoclast differentiation. In our previous study, the PSC extract showed protective effects against oxidative cell death induced by $\mathrm{H}_{2} \mathrm{O}_{2}$. Collectively, these findings indicate that the PSC extract plays a key linkage role in the productions of reactive oxygen species by RANKL. Overall, in this study, the PSC extract showed physiological activities on osteoblast differentiation and osteoclast formation without cytotoxicity. This indicates that the PSC extract could be developed as a health functional food and medicinal agent to prevent bone-related diseases derived from natural materials.



Fig. 5. Tartrate-resistant acid phosphatase (TRAP) staining and activity of receptor activator of nuclear factor kappa-B ligand (RANKL)-induced RAW264.7 osteoclast cells after incubation with pressurized steam-treated Corni Fructus extracts. A, Cell matrix TRAP staining; B, cellular TRAP activity were measured at 7 days.

Abbreviations: GM, growth medium; DM, differentiation medium; DM+PSC, differentiation medium with $10 \mu \mathrm{g} / \mathrm{mL}$ pressurized steam-treated Corni Fructus at 1.2 $\mathrm{kg}_{\mathrm{f}} / \mathrm{cm}^{2}$ and $121^{\circ} \mathrm{C}$ for $2 \mathrm{~h}$

Values are expressed as means \pm SD of triplicate determinations. Bars with different letters indicate significant differences $(p<0.05)$.

\section{References}

1. Gugulethu N, Gerda F, Malefa T, Werner C, Vanessa $S$ (2013) In vitro determination of the anti-aging potential of four southern African medicinal plants. BMC Complementary Altern Med, 13, 304-309

2. Kuro-o M, Matsumura Y, Aizawa H, Kawaguchi H, Suga T, Utsugi T, Ohyama Y, Kurabayashi M, Kaname T, Kume E, Iwasaki H, Lida A, Shiraki-lida T, Nishikawa S, Nagai R, Nabeshima Y (1997) Mutation of the mouse klotho gene leads to a syndrome resembling ageing. Nature, 390, 45-51

3. Rodan GA, Martin TJ (2000) Therapeutic approaches to bone diseases. Science, 289, 1508-1514

4. Teitelbaum SL, Ross FP (2003) Genetic regulation of osteoclast development and function. Nat Rev Genet, 4, 638-649

5. Kim MJ, Im NK, Yu MH, Kim HJ, Lee IS (2011) Effects of extracts from sarcocarp, peels, and seeds of avocado on osteoblast differentiation and osteoclast formation. $\mathbf{J}$ Korean Soc Food Sci Nutr, 40, 919-927

6. Hwang KK, Huh NK, Lee JH (2000) Studies on the signaling molecules in RANK, an osteoclast differentiation receptor. Oral Biol Res, 24, 245-255 
7. Suda T, Nakamura I, Jimi E, Takahashi N (1997) Regulation of osteoclast function. J Bone Miner Res, 12, 869-879

8. Lee JW, Lee IS (2004) Effects of Rubus coreanus Miquel extracts on the activity and differentiation of MC3T3-E1 osteoblastic cell. J Life Science, 14, 967-974

9. Lacey DL, Tan HL, Lu J, Kaufman S, Van G, Qiu W, Rattan A, Scully S, Fletcher F, Juan T, Kelley M, Burgess TL, Boyle WJ, Polverino AJ (2000) Osteopotegerin ligand modulates murine osteoclast survival in vitro and in vivo. J Am Pathol, 157, 435-448

10. Kwak HB, Lee SW, Li YJ, Kim YA, Han SY, Jhon GJ, Kim HH, Lee ZH (2004) Inhibition of osteoclast differentiation and bone resorption by a novel lysophosphatidylcholine derivative, SCOH. Biochem Pharmacol, 67, 1239-1248

11. Nakagawa H, Wachi M, Woo JT, Kato M, Kasai S, Takahashi F, Lee IS, Nagai K (2002) Fenton reaction is primarily involved in a mechanism of (-)-epigallocatechin3-gallate to induce osteoclastic cell death. Biochem Biophys Res Commun, 292, 94-101

12. Basu S, Michaelsson K, Olofsson H, Johansson S, Melhus H (2001) Association between oxidative stress and bone mineral density. Biochem Biophys Res Commun, 288, 275-279

13. Maggio D, Barabani M, Pierandrei M, Polidori C, Catani M, Mecocci P, Senin U, Pacifici R, Cherubini A (2003) Morked decrease in plasma antioxidants in aged osteoporotic women: Results of a cross-sectional study. J Clin Endocrinol Metab, 88, 1523-1527

14. Morton D, Barrett-Conner EL, Schneider DL (2001) Vitamin $\mathrm{C}$ supplement use and bone mineral density in postmenopausal women. J Bone Miner Res, 16, 135-140

15. Seckin D, Liha N, Ertugrul S (2006) Glycaemic control, markers of endothelial cell activation and oxidative stress in children with type 1 diabetes mellitus. Diabetes Res Clin Pract, 73, 191-197

16. Liu L, Sun A, Wu S, Liu R (2009) Preparative purification of morroniside and loganin from Fructus Corni by combination of macroporous absorption resin and HSCCC. J Chromatogr Sci, 47, 333-336

17. Yokozawa T, Park CH, Noh JS, Tanaka T, Cho EJ (2009) Novel action of 7-O-galloyl-D-sedoheptulose isolated from Corni Fructus as a hypertriglyceridaemic agent. J Pharm Pharmacol, 61, 653-661

18. Wang MY, Zhao FM, Peng HY, Lou CH, Li Y, Ding $\mathrm{X}$, Yu XY, Yang GM, Xu DQ, Jiang LH, Zhang X,
Ye LH, Cai BC (2010) Investigation on the morphological protective effect of 5-hydroxymethylfurfural extracted from wine-processed Fructus corni on human L02 hepatocytes. J Ethnopharmacol, 130, 424-428

19. Hsu JH, Wu YC, Liu IM, Cheng JT (2006) Release of acetylcholine to raise insulin secretion in Wistar rats by oleanolic acid, one of the active principles contained in Cornus officinalis. Neurosci Lett, 404, 112-116

20. Endo T, Taguchi H (1973) Study on the constituents of Cornus officinalis Sieb. et Zucc. Yakugaku Zasshi, 93, 30-32

21. Lee SO, Kim SY, Han SM, Kim HM, Ham SS, Kang IJ (2006) Corni fructus scavenges hydroxy radicals and decreases oxidative stress in endothelial cells. J Med Food, 9, 594-598

22. Yamahara J, Mibu H, Sawada T, Fujimura H, Takino S, Yoshikawa M, Kitagawa I (1981) Biologically active principles of crude drugs. Antidiabetic principles of corni fructus experimental diabetes induced by streptozotocin. Yakugaku Zasshi, 101, 86-90

23. Chang JS, Chiang LC, Hsu FF, Lin CC (2004) Chemoprevention against hepatocellular carcinoma of Cornus officinalis in vitro. Am J Chin Med, 32, 717-725

24. Park HM, Hong JH (2017) Physicochemical properties and protective effects of Corni fructus treated with pressurized-steam against $\mathrm{H}_{2} \mathrm{O}_{2}$-induced cytotoxicity on L132 cells. J Korean Soc Food Sci Nutr, 46, 1061-1070

25. Denizot F, Lang R (1986) Rapid colorimetric assay for cell growth and survival. Modifications to the tetrazolium dye procedure giving improved sensitivity and reliability. J Immunol Methods, 22, 271-277

26. Ozeki K, Aoki H, Fukui Y (2008) The effect of adsorbed vitamin $\mathrm{D}$ and $\mathrm{K}$ to hydroxyapatite on ALP activity of MC3T3-E1 cell. J Mater Sci Mater Med, 19, 1753-1757

27. Reinholz GG, Getz B, Pederson L, Sanders ES, Subramaniam M, Ingle JN, S pelsberg TC (2000) Bisphosphonates directly regulate cell proliferation, differentiation, and gene expression in human osteoblasts. Cancer res, 60, 6001-6007

28. Kwon IS, Cho YE, Lomeda RAR, Shin HI, Choi JY, Kang YH, Beattie JH (2010) Zinc deficiency suppresses matrix mineralization and retards osteogenesis transiently with catch-up possibly through Runx 2 modulation. Bone, 46, 732-741

29. Woo JT, Nakagawa $H$, Notoya M, Yonezawa T, Udagawa N, Lee IS, Ohnishi M, Hagiwara H, Nagai K (2004) Quercetin suppresses bone resorption by inhibiting the 
differentiation and activation of osteoclasts. Biol Pharm Bull, 27, 504-509

30. Centrella M, McCarthy TL, Canalis E (1987) Transforming growth factor beta is a bifunctional regulator of replication and collagen synthesis in osteoblast-enriched cell cultures from fetal rat bone. J Biol Chem, 262, 2869-2874

31. Letton RW, Fanti P, Malluche HH (1990) Regulation of 25-hydroxyvitamin $\mathrm{D}_{3}$ metabolism in cultures of osteoblastic cells. J Bone Miner Res, 5, 815-823

32. Stein GS, Lian JB, Owen TA (1990) Relationship of cell growth to the regulation of tissue-specific gene expression during osteoblast differentiation. FASEB J, 4, 3111-3123

33. Ji SH, Ahn DH, Jun MR (2010) Effects of Petasites japonicus and Momordica charantia L.extracton MC3T3-E1 osteoblastic cells. J Korean Soc Food Sci Nutr, 39, 203-209

34. Boskey AL, Roy R (2008) Cell culture systems for studies of bone and tooth mineralization. Chem Rev, 108, 4716-4733

35. Addison WN, Nelea V, Chicatun F, Chien YC, Tran-Khanh N, Buschmann MD, Nazhat SN, Kaartinen MT, Vali H, Tecklenburg MM, Franceschi RT, McKee MD (2015) Extracellular matrix mineralization in murine
MC3T3-E1 osteoblast cultures: An ultrastructural, compositional and comparative analysis with mouse bone. Bone, 71, 244-256

36. Hsu H, Lacey DL, Dunstan CR, Solovyev I, Colombero A, Timms E, Tan HL, Elliott G, Kelley MJ, Sarosi I, Wang L, Xia XZ, Elliott R, Chiu L, Black T, Scully S, Capparelli C, Morony S, Shimamoto G, Bass MB, Boyle WJ (1999) Tumor necrosis factor receptor family member RANK mediates osteoclast differentiation and activation induced by osteoprotegerin ligand. Proc Natl Acad Sci USA, 96, 3540-3545

37. Teitelbaum SL (2000) Bone resorption by osteoclast. Science, 289, 1504-1508

38. Mok SK, Shin HS (1996) The effects of prostaglandin and dibutyryl cAMP on osteoblastic cell activity and osteoblast generation. J Wonkwang Dental Res Inst, 6, 43-67

39. Karst M, Gorny G, Galvin RJ, Oursler MJ (2004) Roles of stromal cell RANKL, OPG, and M-CSF expression in biphasic TGF- $\beta$ regulation of osteoclast differentiation. J Cell Physiol, 200, 99-106

40. Lee NK, Choi YG, Baik JY, Han SY, Jeong DW, Bae YS, Kim N, Lee SY (2005) A crucial role for reactive oxygen species in RANKL-induced osteoclast differentiation. Blood, 106, 852-859 